\title{
Research on Daily Optimal Operation of Pumping Station of South to North Water Transfer Project
}

\author{
Guoqing Sang ${ }^{1, a^{*}}$, Shuxin Song ${ }^{1, b}$, Ying Wang $^{1, c}$, Cuiling Jiao ${ }^{2, d}$ and Guoqing \\ ${ }^{1}$ University of Jinan School of Resources and Environmental Sciences, Jinan 250012, China \\ ${ }^{2}$ East Part of South to North Water Diversion in Shandong CO. LTD, JiNan 250013, China \\ ${ }^{3}$ Shandong Province Water Transfer Engineering Technology Research Center, JiNan 250013, \\ China \\ asangguoqing@163.com, b546084498@qq.com, '625645274@qq.com, d26994016@qq.com, \\ e15866786105@139.com
}

Keywords: Pumping station; Optimal operation; Efficiency; South to North Water Transfer Project

\begin{abstract}
In this paper, in order to make daily operation cost minimum, according to the typical pumping station of the east line of South-to-North Water Transfer Project, the relationship between lift, flow, speed, efficiency of pumping device is analyzed by the model test data. The combination of water-turbine and operation scheme is determined by seeking the optimal operation scheme. The daily optimal operation model of a single-stage pumping station is established by using dynamic programming method. The optimal operation scheme of Han Zhuang pumping station is taken as an example. The results show that the optimal operation scheme can effectively reduce the running electricity cost compared with the present scheme.
\end{abstract}

\section{Introduction}

In recent years, in order to alleviate the shortage of water resources in the north and promote the optimal allocation of water resources, a large number of cross-basin cascades pumping station water conveyance project has been built. Pumping station is the core part of the project and its energy consumption and operating costs is bigger. Therefore, the corresponding need to run energy-saving and potential is also great.

Large-scale pumping stations generally use the planned water distribution method by according to requirement to adjust the water in the intake area and combining with the conveyance capacity of main channel to develop daily water supply plan. The optimization of pumping station daily operation plan is the key link of pumping station economic operation. In this paper, based on the calculation of pumping device efficiency, the daily economic operation model of pumping station is established by considering the factors such as lift change to find the optimal daily operation scheduling scheme and rationally arrange the start-up combination and operation scheme of each unit. Therefore, the operating costs of pumping stations are reduced ${ }^{[1-4]}$.

\section{Analysis and Calculation of Performance Characteristics of Pump device}

According to the model test data of the existing pump system, the performance data of the pump system are obtained by the similar conversion aiming at frequency control pumping station about east route of South-to-North water transfer. By using the B-spline curve fitting method, the comprehensive characteristic curve of the water pumping prototype device can be obtained ${ }^{[5]}$. On this basis, the motor efficiency and transmission efficiency are taken into account, and the comprehensive characteristic curves of the pumping station are obtained, which provide the basic data for the optimization of pumping station operation ${ }^{[6-8]}$. The following describes the efficiency of pumping device, water pump operating conditions to determine the link to conduct a detailed introduction. 
Efficiency of Pump Unit. The efficiency of the pumping device can be calculated on the basis of the efficiency of the pump system to consider the motor efficiency and transmission efficiency, pumping efficiency calculation formula is as follows.

$$
\eta_{\text {st }}=\eta_{\text {pumpAssem }} \times \eta_{\text {trans }} \times \eta_{\text {motor }} \text {. }
$$

Where $\eta_{s t}$ represents the efficiency of the pumping devices, $\eta_{\text {pumpassem }}$ represents the efficiency of the pump system, $\eta_{\text {motor }}$ represents the motor efficiency and $\eta_{\text {trans }}$ represents the transmission efficiency. Large-scale axial flow pumping stations are generally used in the direct connection of the motor and water pump mechanical transmission, $h_{\text {trans }} \gg 100 \%$. Large-scale axial flow pumping stations are generally used low-speed synchronous motor, and it is effective power equipment whose efficiency can be considered basically unchanged from full load to $50 \%$ load.

Determination of Pump Operating Point. The pump system in the $n_{1}$ and $n_{2}$ speed $Q \sim H$ curve similarity point for the $A_{1}$ and $A_{2}$, the pump speed of each $Q \sim H$ curve under the efficiency point of the line as a coordinate through the origin of the quadratic parabola, denoted by $H=k Q^{2}$ given $\mathrm{A}$ point of the lift and flow, you can determine the $\mathrm{k}$ value, so as to determine the equivalent curve through the A point. Then the intersection of equal-efficiency curve and $Q \sim H$ curve can be obtained. The efficiency and speed of A point is $h=h_{1} ; n=\frac{Q}{Q_{1}} n_{1}$.

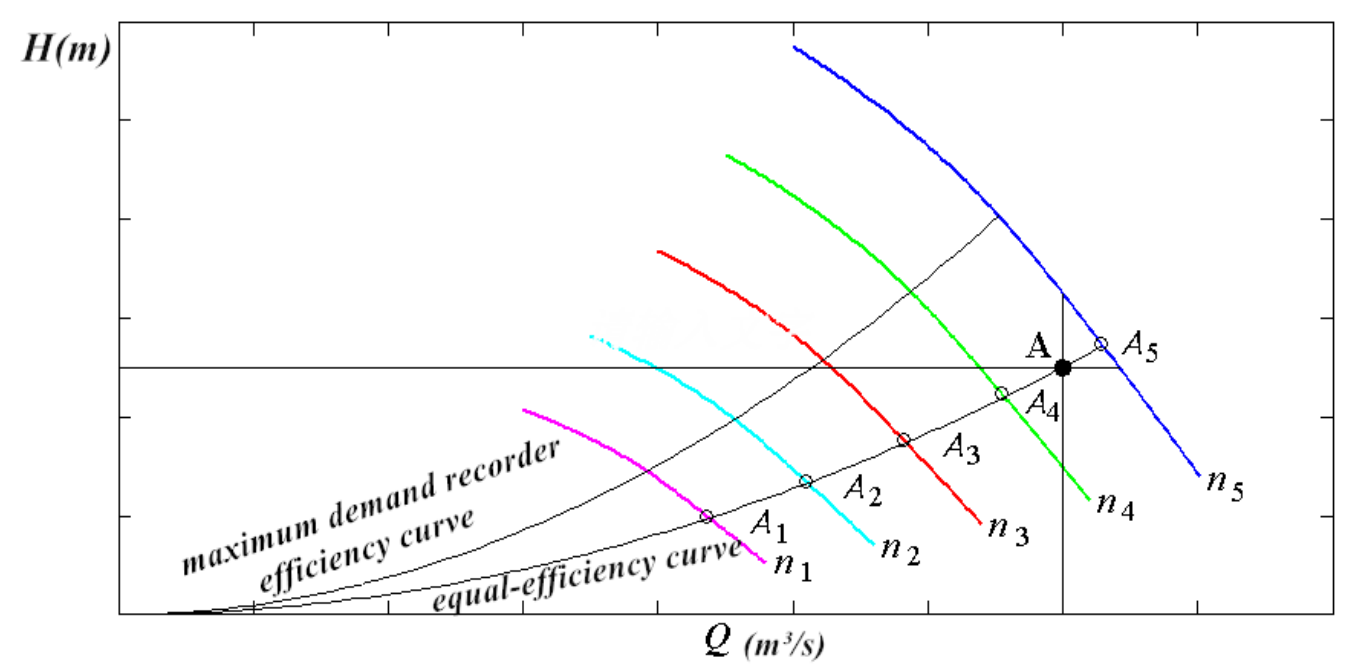

Figure 1. The rotational speed of pump operating point calculation diagram

\section{Construction of Daily Economic Operation Model for Single - stage Pumping Station}

Calculation of Daily Operating Cost for Single - stage Pumping Station. The daily operating cost in this paper refers to the electricity required for normal operation of the pumping station. The daily operating cost of pumping station is expressed as:

$$
C_{d}=\sum_{j=1}^{n} \frac{N_{j}}{\eta_{\text {pump }, j}\left(Q_{j}, H_{j}\right)} \cdot \Delta t_{j} \cdot c_{j}+c_{s} \cdot \lambda .
$$




$$
\eta_{p u m p, j}\left(Q_{j}, H_{j}\right)=\frac{\sum_{i=1}^{m} \rho \cdot g \cdot Q_{i, j} \cdot H_{j}}{\sum_{i=l}^{m} \rho \cdot g \cdot Q_{i, j} \cdot H_{j} / \eta_{\text {set }, i, j}} .
$$

Where $Q_{i j}$ represents the flow of pumping device $i$ in period $j ; Q_{j}$ represents total flow in period $j ; H_{j}$ represents lift in period $j ; N_{j}$ represents the sum of the effective power of multiple pumping devices in period $j ; \Delta t_{j}$ represents lengths of the time interval; $c_{j}$ represents unit price; $c_{s}$ represents penalty unit price; $\lambda$ represents total number of switching machine during flow adjustment; $\eta_{\text {set }, i j}$ represents the efficiency; $\eta_{\text {pump }, j}\left(Q_{j}, H_{j}\right)$ represents overall operational efficiency.

Daily Economic Operation Model of Single Stage Pumping Station. The daily pumping amount of the pumping station is fixed, and the minimum operating cost is taken as the target. The blade angle (speed) of each unit in the pumping station is taken as the decision variable, and the time of the pumping station is calculated. Distribution and the corresponding pumping station internal operation program (number of switching machines, blade angle, and speed), the optimization model is as follows:

(1) Objective function

$$
\begin{gathered}
\operatorname{MinC}_{d}=\operatorname{Min} \sum_{j=1}^{n} \frac{N_{j}}{\eta_{\text {pump }, j}\left(Q_{j}, H_{j}\right)} \cdot \Delta t_{j} \cdot c_{j}+c_{s} \cdot \lambda . \\
\operatorname{Max}_{\text {pump }}=\operatorname{Max} \frac{\sum_{i=1}^{m} \rho \cdot g \cdot Q_{i}\left(\theta_{i}, n_{i}\right) \cdot H_{j}}{\sum_{i=1}^{m} \rho \cdot g \cdot Q_{i}\left(\theta_{i}, n_{i}\right) \cdot H_{j} / \eta_{\text {set }, i}} .
\end{gathered}
$$

Where $\eta_{\text {pump }, j}\left(Q_{j}, H_{j}\right)$ is optimal efficiency; $T W$ represents total water flow.

(2) Constraints

Day total water constraint $\quad T W=\sum_{j=1}^{n} Q_{\mathrm{j}} \cdot \Delta t$

Total Flow Constraint of Pumping Station $\quad Q_{j}=\sum_{i=1}^{m} Q_{i, j}$

Unit power constraint $\quad \operatorname{MinN}_{\mathrm{ij}} \leq N_{\mathrm{ij}} \leq \operatorname{Max} N_{\mathrm{ij}}$

Overcurrent restraint $Q_{\text {Min }} \leq Q_{i j} \leq Q_{\text {Max }}$

Model Solving. In this paper, the dynamic programming method based on discrete interval is used to solve the optimal decision problem of each model. The dynamic programming method is one of the basic mathematical methods in optimization techniques, which is created by the American mathematician Bellman R. Bellman. It divides the complex initial problem into several sub-problems, which are solved step by step. The dynamic programming method based on interval discretization is used to solve each subsystem in this paper. The calculation points of the general dynamic programming method are discrete. When the discrete steps of the decision points are not equal in the adjacent stage, there is no decision combination for a given state, which leads to the exponential increase of the discrete points. In order to avoid this problem, the state variables are replaced by interval discretization instead of point discretization.

\section{An Example of Optimizing Economic Operation of Han Zhuang Pumping Station on the Eastern Route of the South - to - North Water Transfer Project}

Overview of Han Zhuang Pumping Station. Han Zhuang pumping station hub project is located in the west of Zaozhuang. The highest design lift of Han Zhuang pumping station is $4.15 \mathrm{~m}$, and the lowest lift is $2.25 \mathrm{~m}$. The stand-alone design flow of Han Zhuang pumping station is $31.5 \mathrm{~m}^{3} / \mathrm{s}$. The pump is driven 
by $10 \mathrm{kV}$ high voltage variable frequency motor. The power frequency is $125 \mathrm{r} / \mathrm{min}$. The motor power is $2000 \mathrm{~kW}$, and the total installed capacity of the pumping station is $10000 \mathrm{~kW}$.

Considering the factors of time-sharing tariff cycle and lift changes, Han Zhuang pumping station is divided into four periods a day by using the planned water transfer model. The lift and price changes in Table 1.

Table 1 The optimization period division and lift, price $(b=0.7496)$

\begin{tabular}{ccccc}
\hline $\begin{array}{c}\text { Optimization } \\
\text { period }\end{array}$ & 1 & 2 & 3 & 4 \\
\hline Period & $8: 00-11: 30$ & $11: 30-18: 30$ & $18: 30-23: 30$ & $23: 30-8: 00$ \\
Time-period & $3.5 \mathrm{~h}$ & $7 \mathrm{~h}$ & $5 \mathrm{~h}$ & $8.5 \mathrm{~h}$ \\
Lift & 4.2 & 3.9 & 4.0 & 4.1 \\
Price & $1.6 \mathrm{~b}$ & $1 \mathrm{~b}$ & $1.6 \mathrm{~b}$ & $0.4 \mathrm{~b}$ \\
Types & Peak & Value period & Peak & Low ebb \\
\hline
\end{tabular}

According to the performance data of pump model of Han Zhuang pumping station, the head-flow-efficiency and head-flow-speed performance data of pumping station can be obtained according to the method of section 1 , and the basic data are optimized.

Calculation and Analysis of Daily Economic Operation Plan of Single-stage Pump. According to the optimization model, the flow distribution of Han Zhuang pumping station is calculated at each time, and the optimal operation of each unit is shown in the table below. Program in Table 2, Table 3.

Table 2 Han Zhuang pumping station in each period of optimal flow allocation scheme

\begin{tabular}{ccccccccc}
\hline & & & \multicolumn{3}{c}{ Status of the program } & \multicolumn{3}{c}{ Optimization } \\
\cline { 4 - 9 } Period & $\begin{array}{c}\text { Lift } \\
(\mathrm{m})\end{array}$ & Price & $\begin{array}{c}\text { Flow } \\
\text { distribution } \\
(\mathrm{m} 3 / \mathrm{s})\end{array}$ & $\begin{array}{c}\text { Pumping } \\
\text { station } \\
\text { efficiency }\end{array}$ & $\begin{array}{c}\text { Unit } \\
\text { cost } \\
(\text { yuan })\end{array}$ & $\begin{array}{c}\text { Flow } \\
\text { distribution } \\
(\mathrm{m} 3 / \mathrm{s})\end{array}$ & $\begin{array}{c}\text { Pumping } \\
\text { station } \\
\text { efficiency }\end{array}$ & $\begin{array}{c}\text { Unit } \\
\text { cost }\end{array}$ \\
\hline 8:00-11:30 & 4.2 & $1.6 \mathrm{~b}$ & 110 & 0.777 & & 55 & 0.778 & \\
$11: 30-18: 30$ & 3.9 & $1 \mathrm{~b}$ & 110 & 0.785 & & 132 & 0.796 & \\
$18: 30-23: 30$ & 4.0 & $1.6 \mathrm{~b}$ & 110 & 0.783 & & 87 & 0.791 & \\
$23: 30-8: 00$ & 4.1 & $0.4 \mathrm{~b}$ & 110 & 0.781 & & 128 & 0.796 & \\
\hline
\end{tabular}


Table 3 Han Zhuang pumping station within a day each time optimal operation scheme

\begin{tabular}{|c|c|c|c|c|c|c|}
\hline Period & $\operatorname{Lift}(\mathrm{m})$ & $\begin{array}{l}\text { Flow } \\
\left(\mathrm{m}^{3} / \mathrm{s}\right)\end{array}$ & $\begin{array}{c}\text { Efficiency } \\
\text { of pumping } \\
\text { station }\end{array}$ & $\begin{array}{c}\text { Set } \\
\text { discharge }\end{array}$ & $\begin{array}{c}\text { Single } \\
\text { unit } \\
\text { efficiency }\end{array}$ & Speed $(\mathrm{r} / \mathrm{min})$ \\
\hline \multirow[t]{4}{*}{$8: 00-11: 30$} & \multirow[t]{4}{*}{4.2} & \multirow[t]{4}{*}{55} & \multirow[t]{4}{*}{0.77785} & 28 & 0.7819 & 116.7922 \\
\hline & & & & 27 & 0.7737 & 115.2388 \\
\hline & & & & 1 & 1 & 1 \\
\hline & & & & / & / & / \\
\hline \multirow[t]{4}{*}{$11: 30-18: 30$} & \multirow[t]{4}{*}{3.9} & \multirow[t]{4}{*}{132} & \multirow[t]{4}{*}{0.7955} & 33 & 0.7955 & 124.2423 \\
\hline & & & & 33 & 0.7955 & 124.2423 \\
\hline & & & & 33 & 0.7955 & 124.2423 \\
\hline & & & & 33 & 0.7955 & 124.2423 \\
\hline \multirow{4}{*}{$18: 30-23: 30$} & \multirow[t]{4}{*}{4} & \multirow[t]{4}{*}{87} & \multirow[t]{4}{*}{0.7965} & 29 & 0.791 & 116.3386 \\
\hline & & & & 29 & 0.791 & 116.3386 \\
\hline & & & & 29 & 0.791 & 116.3386 \\
\hline & & & & 1 & 1 & 1 \\
\hline \multirow[t]{4}{*}{$23: 30-8: 00$} & \multirow[t]{4}{*}{4.1} & \multirow[t]{4}{*}{128} & \multirow[t]{4}{*}{0.7965} & 32 & 0.7965 & 123.6463 \\
\hline & & & & 32 & 0.7965 & 123.6463 \\
\hline & & & & 32 & 0.7965 & 123.6463 \\
\hline & & & & 32 & 0.7965 & 123.6463 \\
\hline
\end{tabular}

\section{Conclusion}

In the case of a certain total daily water supply, the price of electricity, water flow, lift and pumping efficiency in each period are the main factors that affect the daily operation cost of pumping station. Among them, comparing to pump efficiency and lift changes, time-sharing price is the main factor that affects flow distribution in time period and daily operation cost due to different price differences in different periods is bigger.

When the total daily water supply and the lift change are constant, the operation cost can be reduced significantly by optimizing the operation. Taking the typical working conditions as an example, the operating cost of Han Zhuang pumping station is 0.009 yuan $/ \mathrm{m}^{3}$, which is $12 \%$ less than that before optimization.

In this paper, the efficiency of the pumping device is calculated from the pump model data, and the next step should be in the actual operation of the pumping station operating point of the operating parameters, the performance of the check to ensure the reliability of the optimization program ${ }^{[9-10]}$.

\section{Acknowledgements}

This work was supported by National Natural Science Foundation of China (No.51409119), Project Supported by National Science and Technology Ministry(ID:2015BAB07B03,2015BAB07B02) and Water Conservancy research and Technology Promotion Project of Shandong of China (ID:SDSLKY201505).

\section{References}

[1] X.L. Feng, B.Y. Qiu and H.T. Huang: Research headway on large pump station economical operation. Fluid Machinery. 34 (2006) 4, 32-37. (in Chinese)

[2] J.L. Cheng, L.H. Zhang, R.T. Zhang, Y. Gong, H.G. Zhu and D.S. Deng. Optimal methodology of single-unit variable speed operation in pumping station. Transactions of the Chinese Society for Agricultural Machinery. 41 (2010) 3, 72-76. (in Chinese) 
[3] J.L. Cheng, L.H. Zhang, R.T. Zhang and Y. Gong: Optimal methodology of single-unit daily operation. Journal of Hydraulic Engineering. 41 (2010) 4, 499-503. (in Chinese)

[4] G.Q. Sang, S.L. Cao, R. Guo, Q.S. Guan and X.Y. Bai: Research on optimization of whole efficiency of cascade pumping station water-delivery system. Systems Engineering-Theory \& Practics. 34 (2014) 8, 2179-2185. (in Chinese)

[5] L. Zhang, Y.H. Yu and X.M. Jiang: Fitting method for pump efficiency characteristic curve based on B-spline. Drainage and Irrigation Machinery. 24 (2006) 3, 9-11. (in Chinese)

[6] H.T. Huang, X.L. Feng and B.Y. Qiu: Analysis on total station operating efficiency of the eastern route of South-to-North water transfer project. South-to-North Water Transfer and Water Science \& Technology. 3 (2005) 3, 11-14. (in Chinese)

[7] G.Q. Sang, L. Zhang, Q.J. Dong and J. Zhang: Calculation and research on pumping equipment performance of blade adjustment pump station. South-to-North Water Transfer and Water Science \& Technology. 10 (2012) 4, 14-17. (in Chinese)

[8] S.L. Chen, J. Rui, Q. Xu and Y.M. Jin: Daily optimal operation for pumping stations. Water Resources and Power. 21 (2003) 3, 82-83. (in Chinese)

[9] X.P. Long, J.M. Zhu, M.Q. Liu and L.C. Zhou: Computation for stress and deformation of concrete slab in rock-fill dam in consideration of soil anisotropy,. Journal of Hydraulic Engineering. 6 (2004) 11, 27-32. (in Chinese)

[10]D.F. Yan: Pumping Station Project (China Water \& Power Press, China 2005). (in Chinese) 